\title{
PENGEMBANGAN E-MODUL SISTEM REM UNTUK SISWA SEKOLAH MENENGAH KEJURUAN
}

\author{
Dianna Ratnawati ${ }^{1}$, Rusdi Martono ${ }^{2}$, Rabiman $^{3}$ \\ ${ }^{1,3}$ Program Studi Pendidikan Teknik Mesin Universitas Sarjanawiyata Tamansiswa; ${ }^{2}$ SMK YAPPI Wonosari \\ Email: dianna.ratnawati@ustjogja.ac.id
}

\begin{abstract}
E-module has become a form of learning media that displays online reference, which is considered as more attractive and interactive compared to printed books and modules. The development of e-module actualizes the use of technology to facilitate access to science literacy that is inline to the industrial revolution 4.0. This study aims to develop an e-module of brake system for class XI vocational high school students. The research method used is Research and Development. The stages of e-module development are: define, design, develop, and disseminate. The instruments for data collection are questionnaires with quantitative descriptive analysis techniques. The feasibility test of the brake system e-module shows that the results of the evaluation of media experts obtained a percentage of $82 \%$, assessment of material experts by $85 \%$, and field test results by $85 \%$. It can be concluded that the e-module developed is suitable to be used to facilitate the learning process of brake system in vocational high school.
\end{abstract}

Keywords: e-module, brake system, learning media

\begin{abstract}
ABSTRAK
E-modul menjadi salah satu media pembelajaran yang menyajikan bahan referensi online secara menarik dan interaktif dibandingkan dengan media cetak seperti buku atau modul. Pengembangan e-modul merupakan aktualisasi dari pemanfaatan teknologi untuk memudahkan akses literasi bidang ilmu pengetahuan yang selaras dengan revolusi industri 4.0. Penelitian ini bertujuan untuk mengembangkan e-modul sistem rem untuk siswa SMK kelas XI. Metode penelitian yang digunakan adalah Research and Development. Tahapan pengembangan e-modul meliputi: define, design, develop, dan disseminate. Instrumen pengumpulan data menggunakan angket dengan teknik analisis deskriptif kuantitatif. Uji kelayakan e-modul sistem rem ini menunjukkan bahwa hasil penilaian ahli media diperoleh persentase $82 \%$, penilian ahli materi sebesar $85 \%$, dan hasil uji lapangan sebesar 85\%. Dengan demikian dapat disimpulkan bahwa e-modul yang dikembangkan layak digunakan untuk mendukung pembelajaran sistem rem siswa SMK.
\end{abstract}

Kata kunci: e-modul, sistem rem, media pembelajaran

\section{PENDAHULUAN}

Pendidikan kejuruan adalah sistem pendidikan yang menuntut peserta didiknya untuk menguasai kompetensi tertentu. Dalam hal ini siswa Sekolah Menengah Kejuruan (SMK) dituntut untuk menguasai keterampilan tertentu agar siap kerja. Dalam menjamin kualitas lulusannya sangat dipengaruhi oleh kurikulum, tenaga pendidik, proses pembelajaran, sarana dan prasarana, manajemen sekolah, lingkungan sekolah dan kerja sama dengan industri. Lebih lanjut proses pembelajar perlu didukung bahan ajar disesuaikan dengan kompetensi yang dibutuhkan agar nantinya lulusan pendidikan dapat diterima di dunia kerja.

Berdasarkan studi pendahuluan di SMK YAPPI Wonosari didapati bahwa bahan ajar yang digunakan guru pada mata pelajaran sistem rem menggunakan manual book New Step 1 Toyota Training Manual. Dengan menggunakan bahan ajar cetak berdampak pada respon siswa yang bervariasi. Sebagian ada yang antusias, namun tidak sedikit pula yang kurang termotivasi. Dari sisi kepahaman, lebih dari separuh siswa yang belum bisa menguasai secara tuntas. Padahal penguasaan teoritis 
terhadap mata pelajaran sistem rem akan sangat mendukung saat nantinya siswa melakukan pembelajaran praktikum.

Bahan ajar dapat disajikan melalui media pembelajaran online agar lebih menarik, interaktif dan mudah diakses seperti modul pembelajaran elektronik (e-modul) (Devi, Poppy Kamalia, Renny Sofiraeni, 2009). Emodul adalah modul cetak yang ditransformasikan dalam perangkat digital dan didesain agar lebih interaktif dengan memuat unsur multimedia. Akses dan penggunaannya dilakukan melalui alat elektronik seperti komputer, laptop, tablet, dan smartphone (Oktavia, Budhi, zaunul, rahadian, guspatni, putra, ananda, 2018). Untuk dapat menampilkan media interaktif e-modul dapat dibuat dengan program e-book. Jan O. Borchers (1999) mendefinisikan e-book sebagai berikut "an electronik book, or e-book, is a portable hardware and software system that can display large quantities of readable textual information to the user, and that lets user navigate through this information".

Pengembangan e-modul yang dikemas secara elektronik dapat memudahkan siswa dalam mempelajarinya secara mandiri dibandingkan dengan modul cetak. e-modul dapat memasukkan unsur tambahan yang menjadi value added yakni misalnya berupa audio/rekaman suara, gambar gerak dan kuis yang dirancang dalam bentuk umpan balik ketika siswa menjawabnya. E-modul pada dasarnya memiliki karakteristik yang sama dengan modul cetak seperti menurut Lestari (2013) diantaranya: (1) mampu membelajarkan siswa secara mandiri, (2) materi yang disajikan mencakup satu unit kompetensi atau sub kompetensi secara utuh, (3) modul yang dikembangkan tidak tergantung pada media lain atau tidak harus digunakan bersama-sama dengan media pembelajaran lain, (4) memiliki daya adaptif yang tinggi terhadap perkembangan ilmu dan teknologi, modul hendaknya bersahabat dengan pemakainya. Lebih lanjut e-modul juga memiliki karakteristik portable atau bisa dibawa ke manapun hanya dengan disimpan di dalam USB atau membukanya secara online. Suarsana dan mahayukti (2013) menyimpulkan bahwa dalam temuannya e-modul berpengaruh pada peningkatan keterampilan berfikir kritis pada siswa dan mendapat respon positif.

Tujuan dari penelitian adalah mengembangkan e-modul sistem rem untuk media pembelajaran siswa kelas XI TKR di SMK YAPPI Wonosari. Adapun e-modul yang dikembangkan pada penelitian ini yakni memadukan unsur gambar, visual dan kuis.

\section{METODE}

Jenis penelitian ini adalah Research and Development (R\&D) yang menggunakan model 4-D dengan tahapan meliputi: define (pendefinisian), design (perancangan), develop (pengembangan), dan dessiminate (penyebaran). Produk yang dihasilkan adalah bahan ajar online berupa e-modul sistem rem untuk siswa kelas XI kompetensi keahlian Teknik Kendaraan Ringan di SMK YAPPI Wonosari. Instrumen yang digunakan untuk uji kelayakan produk berupa angket. Sedangkan subjek penelitian adalah ahli media, ahli materi, dan siswa kelas XI. Teknik analisis data adalah deskriptif kuantitatif. Data yang diperoleh dari subjek penelitian dianalisis skornya menggunakan rating scale dengan rumus sebagai berikut.

$\mathrm{P}=\frac{\text { jumlah skor hasil pengumpulan data }}{\text { jumlah skor kriterium }} x 100 \%$

Keterangan :

$\mathrm{P}=$ Persentase kelayakan modul

Skor kriterium $=$ jumlah perolehan skor

Selanjutnya hasil perhitungan diatas diinterpretasikan dengan skala interpretasi berikut: 
Tabel 1. Skala interpretasi rating scale

\begin{tabular}{ll}
\hline Prosentase & Keterangan \\
\hline $75 \%<\mathrm{P}<100 \%$ & Baik \\
$50 \%<\mathrm{P} \leq 75 \%$ & Cukup Baik \\
$25 \%<\mathrm{P} \leq 50 \%$ & Kurang Baik \\
$0 \%<\mathrm{P} \leq 25 \%$ & Tidak Baik \\
\hline
\end{tabular}

Keterangan :

Baik = Layak/ tidak perlu revisi

Cukup baik = Cukup layak/ revisi sebagian kecil

Kurang baik = Kurang layak/ revisi sebagian besar

Tidak baik = Tidak layak/ revisi keseluruhan

Lebih lanjut, desain penelitian dan emodul dapat lihita pada Gambar 1 dan Gambar 2.

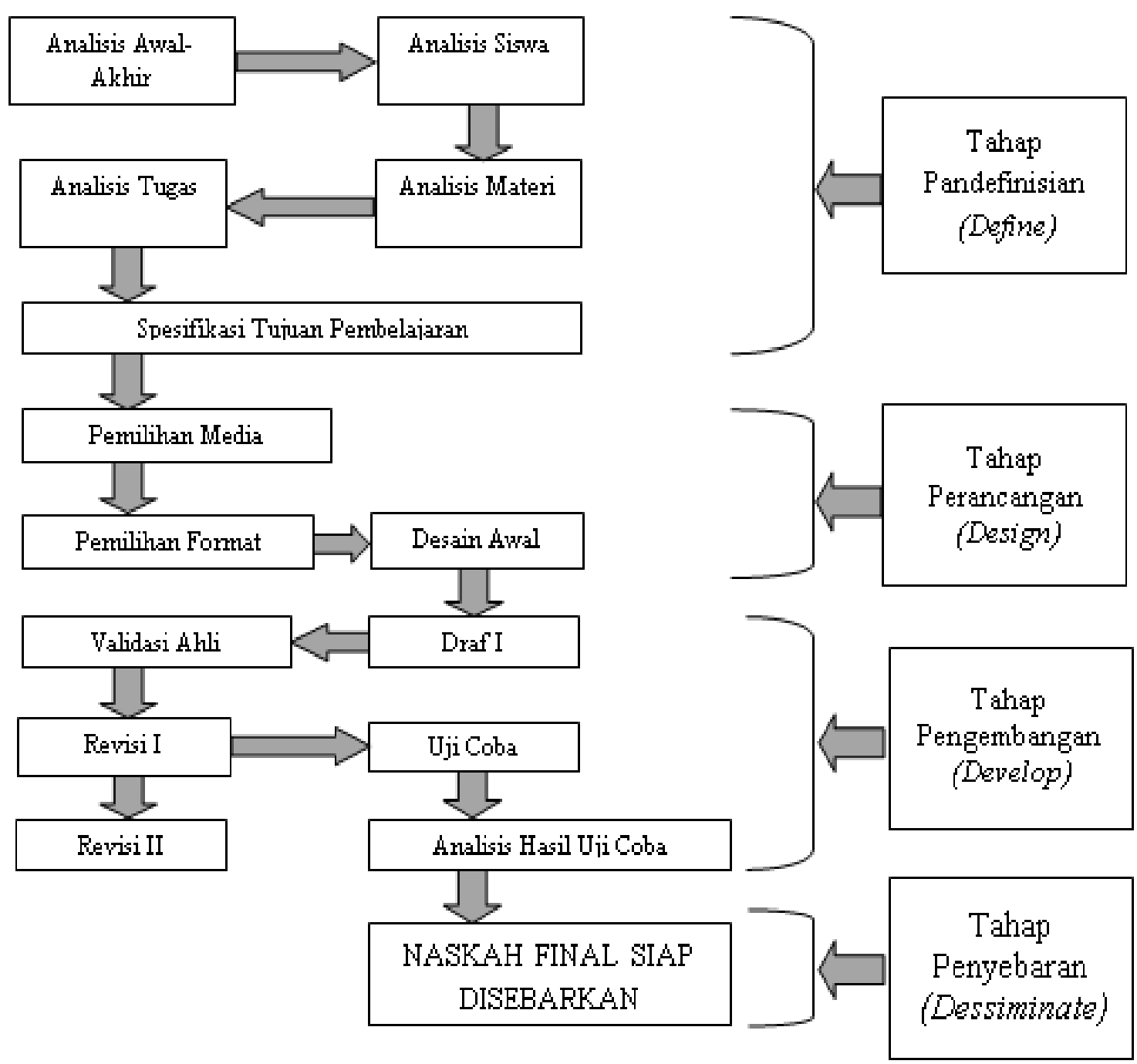

Gambar 1. Skema tahap pengembangan model 4-D 


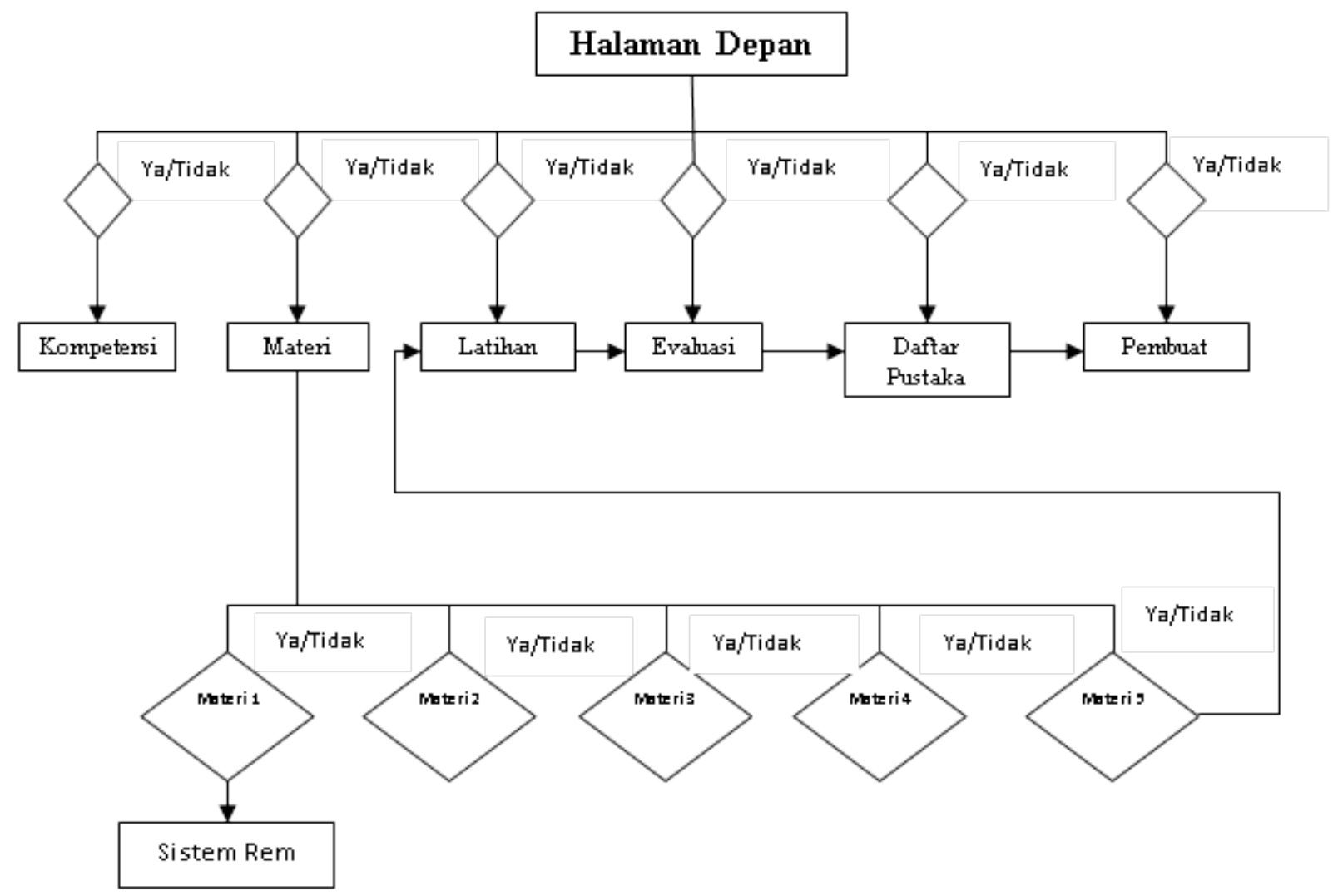

Gambar 2. Flow Chart e-modul sistem rem

Software yang dipilih untuk mengembangankan $e$-modul ini diantaranya lectora, phothoshop, coreldraw dan flash. Hasil produk akan dipublish dalam bentuk SCORM dan AICC agar dapat digunakan untuk pembelajaran $e$-learning. Melalui media pembelajaran e-modul ini siswa dapat mengaksesmateri sistem rem dan latihan soal serta langsung dapat melihat hasil evaluasi.

\section{HASIL DAN PEMBAHASAN}

Produk hasil penelitian ini berupa $e$ modul berbasis web yang langsung terintegrasi dengan web resmi SMK YAPPI Wonosari. Lebih spesifik e-modul menyajikan materi bahasan sistem rem, latihan soal dan evaluasi yang dapat diakses pada laman http://smkyappiwns.sch.id/e-modul-sistem-rem. Tampilan emodul ini dapat dilihat pada Gambar 3.

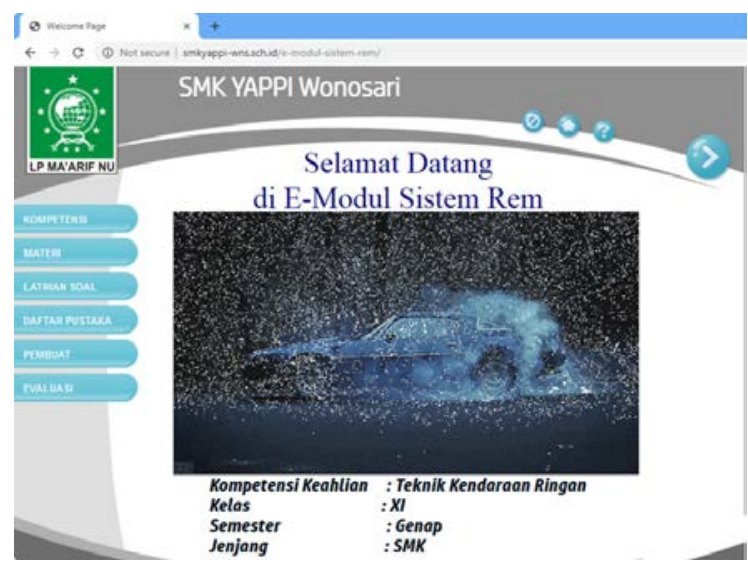

Gambar 3. Tampilan awal web e-modul

Siswa dapat mengoperasikan e-modul dengan mengklik tombol menu yang ada di samping kiri tampilan e-modul (kompetensi, materi, latihan soal, daftar pustaka, pembuat, dan evaluasi 


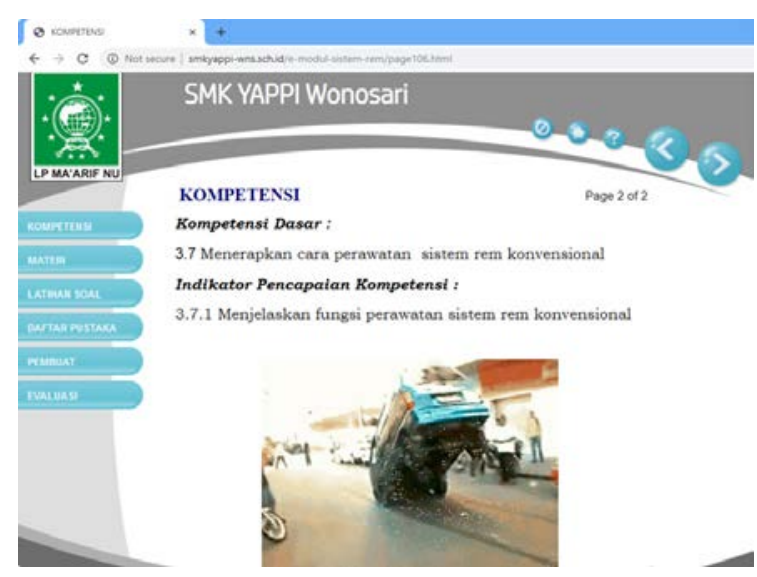

Gambar 4. Tampilan menu kompetensi

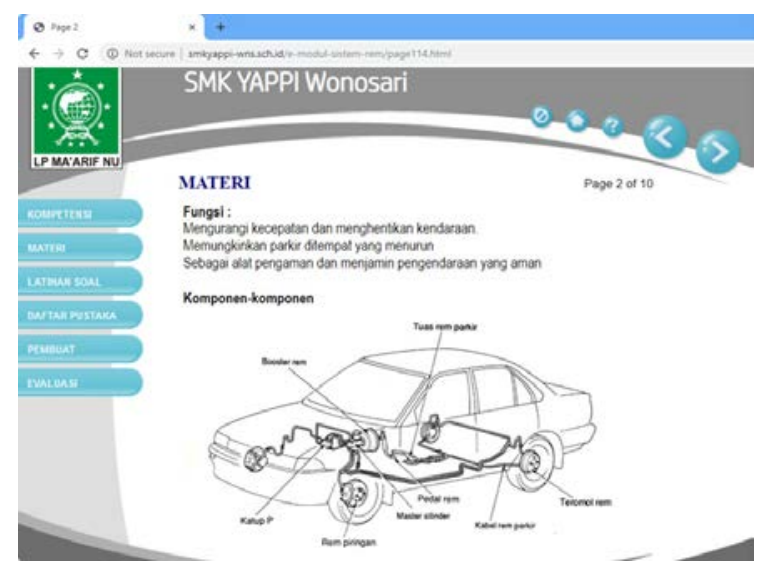

Gambar 5. Tampilan isi materi

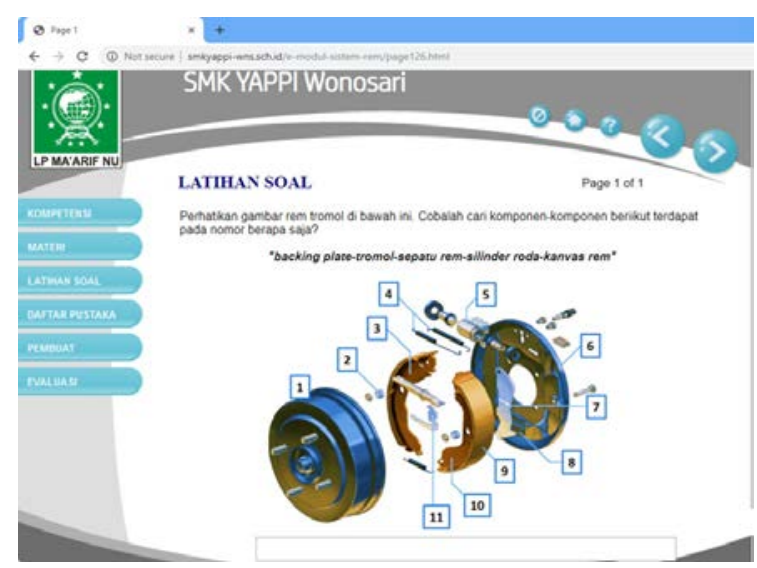

Gambar 6. Tampilan latihan soal

Pada halaman latihan soal, siswa dapat berlatih mengerjakan soal sebelum nantinya mengerjakan evaluasi akhir.

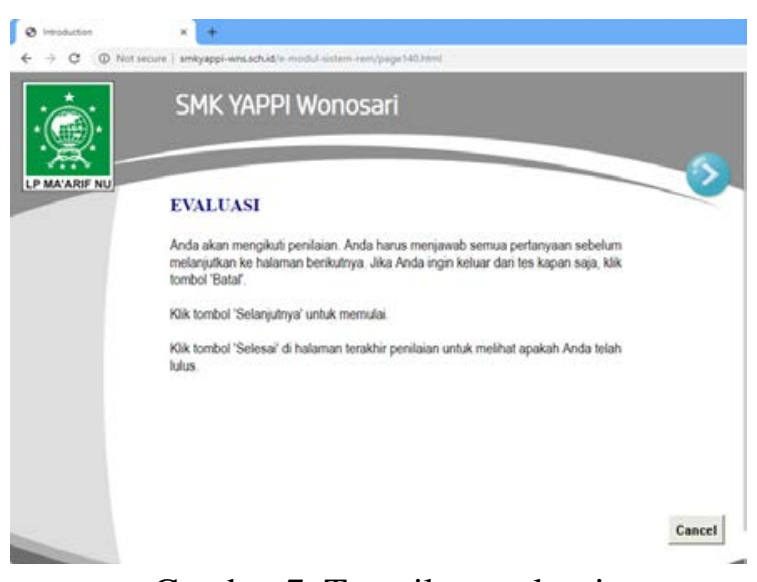

Gambar 7. Tampilan evaluasi

Pada halaman evaluasi, siswa dapat mengerjakan soal evaluasi sebagai penilaian akhir setelah selesai mempelajari e-modul dan hasil nya langsung dapat dilihat secara transparan sehingga dapat memotivasi siswa untuk meningkatkan prestasinya.

Tingkat kelayakan e-modul sistem rem ini dilihat dari rekapitulasi hasil penilaian produk oleh ahli materi, ahli media dan siswa kelas XI SMK YAPPI Wonosari. Hasil penilaian dapat dilihat pada gambar berikut.

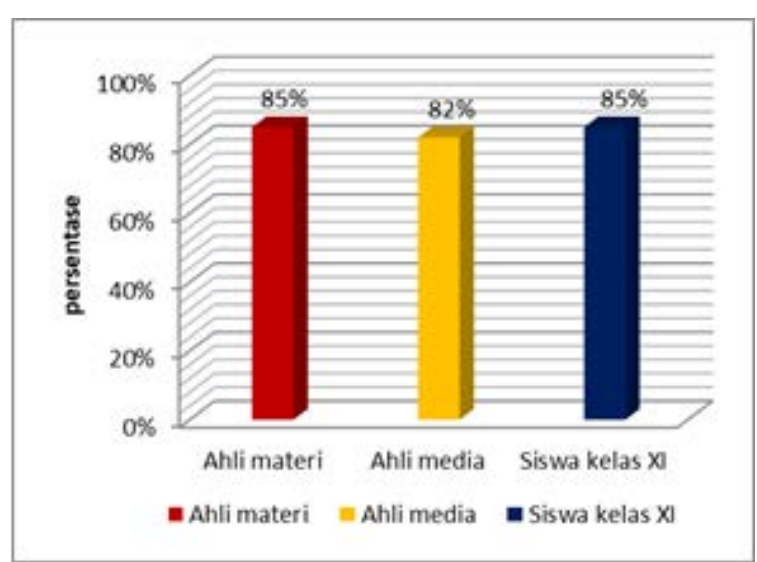

Gambar 8. Hasil uji produk

Dengan rentang perolehan persentase penilaian uji e-modul yaitu 82\%-85\% menunjukkan produk layak digunakan untuk menunjang pembelajaran siswa. Lebih lanjut data hasil penilaian ahli dapat dilihat pada Tabel 2 dan 3. 
Tabel 2. Hasil penilaian ahli materi

\begin{tabular}{clccc}
\hline No & Komponen & Skor & $\begin{array}{c}\text { Skor } \\
\text { kriterium }\end{array}$ & $\begin{array}{c}\text { Persen. } \\
(\%)\end{array}$ \\
\hline 1 & Kualitas isi & 45 & 55 & $82 \%$ \\
2 & $\begin{array}{l}\text { Kualitas } \\
\text { instruksional }\end{array}$ & 9 & 10 & $90 \%$ \\
\hline & Total & 54 & 65 & $85 \%$ \\
\hline
\end{tabular}

Tabel 3. Hasil penilaian ahli media

\begin{tabular}{clccc}
\hline No & Komponen & Skor & $\begin{array}{c}\text { Skor } \\
\text { kriterium }\end{array}$ & $\begin{array}{c}\text { Persen. } \\
\text { (\%) }\end{array}$ \\
\hline 1 & $\begin{array}{l}\text { Komunika } \\
\text { si visual }\end{array}$ & 23 & 30 & $77 \%$ \\
2 & Teknis & 14 & 15 & $93 \%$ \\
\hline & Total & 37 & 45 & $82 \%$ \\
\hline
\end{tabular}

Data hasil uji coba produk pada siswa kelas XI dapat dilihat pada Tabel 4.

Tabel 4. Hasil uji coba e-modul pada siswa

\begin{tabular}{clccc}
\hline No & Komponen & Skor & $\begin{array}{c}\text { Skor } \\
\text { kriterium }\end{array}$ & $\begin{array}{c}\text { Persen. } \\
(\%)\end{array}$ \\
\hline \multirow{2}{1}{$\begin{array}{l}\text { Efisiensi } \\
\text { dan } \\
\text { efektifitas }\end{array}$} & 508 & 600 & $85 \%$ \\
2 & Teknis & 381 & 450 & $85 \%$ \\
\hline & Total & 889 & 1050 & $85 \%$ \\
\hline
\end{tabular}

Hasil uji coba menunjukkan bahwa emodul sistem rem ini memiliki beberapa keunggulan, yaitu: (1) penggunaan yang mudah, (2) materi yang relevan, (3) akses penggunanan e-modul bisa kapan saja dan dimana saja dibuka dan bisa menggunakan komputer ataupun hp android siswa, (4) menarik untuk dibaca, (5) memotivasi untuk terus belajar karena dilengkapi dengan evaluasi.

Keunggulan tersebut tentu dapat meningkatkan prestasi belajar siswa dan memudahkan para siswa dalam belajar secara mandiri. Hal ini selaras dengan pernyataan Sadiman (2014) bahwa kegiatan belajar mengajar yang menggunakan media online lebih efektif karena pembelajaran berpusat pada siswa. Lebih lanjut Setuju dan Slamet Priyanto (setuju, dan priyanto, 2015) menyatakan bahwa melalui penggunaan media yang tepat, maka semua objek dapat disajikan kepada peserta didik. Media dapat menghasilkan keseragaman pengamatan dapat menanamkan konsep dasar yang benar, konkrit, dan realistis, media akan membangkitkan keinginan dan minat baru, membangkitkan motivasi dan merangsang anak untuk belajar, memberikan pengalaman yang menyeluruh secara konkrit maupun abstrak.

Produk e-modul ini telah dideseminasikan pada guru produktif di SMK YAPPI Wonosari Gunungkidul, Yogyakarta dan mendapatkan respon sangat positif.

\section{SIMPULAN}

E-modul yang telah dikembangkan layak digunakan untuk media pembelajaran sistem rem yang menarik dan interaktif bagi siswa SMK.

\section{DAFTAR RUJUKAN}

Borchers, J. O. (1999). Electronic Books: Definition, Genres, Interaction Design Patterns. Austria: Linz University.

Devi, Poppy Kamalia, Renny Sofiraeni, dan K. (2009). Pengembangan Perangkat Pembelajaran. Bandung: P4TK IPA.

Lestari, I. (2013). Pengembangan Bahan Ajar Berbasis Kompetensi. Padang: Akademia Permata.

Oktavia, Budhi, zaunul, rahadian, guspatni, putra, ananda. (2018). Pengenalan Dan Pengembangan E-Modul Bagi Guru- Guru Anggota MGMP Kimia Dan Biologi Kota Padang Panjang.

Sadiman, A. S. (2014). Media Pendidikan. jakarta: Rajawali Pers. 
Setuju, dan priyanto, S. (2015). Penerapan Media Pembelajaran Multimedia Dalam Upaya Meningkatkan Efektifitas Pembelajaran Pada Mata Pelajaran Gambar Teknik Mesin I Kelas X Pemesinan Di Smk Muhammadiyah Prambanan. Taman Vokasi, 1(1), 84-94.
Suarsana I, M. \& Mahayukti, G. A. (2013). Pengembangan E-Modul Berorientasi Pemecahan Masalah Untuk Meningkatkan Keterampilan Berpikir Kritis Mahasiswa. Jurnal Pendidikan Indonesia, 2(2), 270275. 